Document downloaded from:

http://hdl.handle.net/10251/99986

This paper must be cited as:

Carlos Alberola, S.; A. Querol; Gallardo Bermell, S.; Sanchez Saez, F.; Villanueva López, JF.; Martorell Alsina, SS.; Verdú Martín, GJ. (2016). Post-test analysis of the ROSA/LSTF and PKL counterpart tests. Nuclear Engineering and Design. 297:81-94.

doi:10.1016/j.nucengdes.2015.10.028

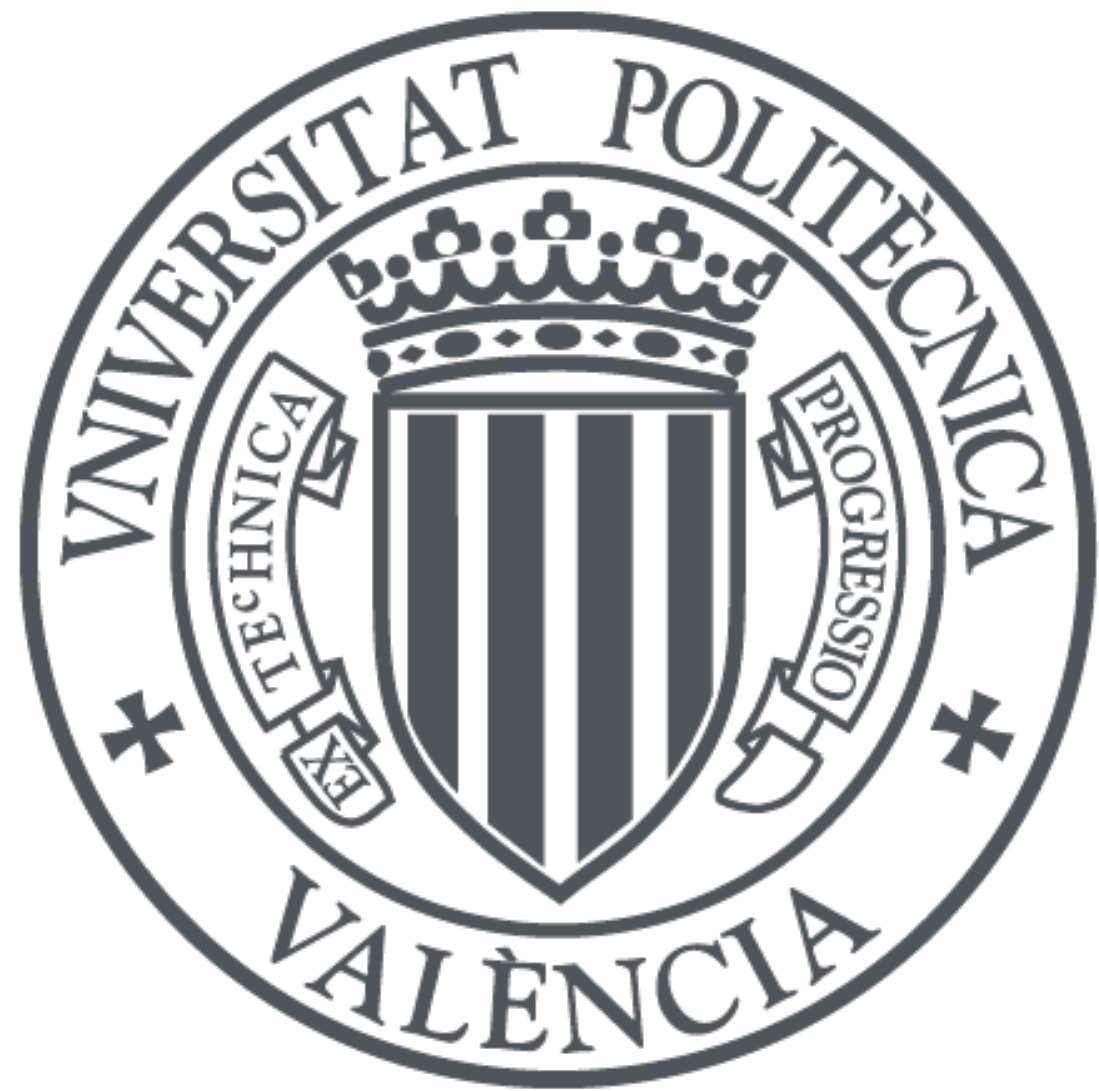

The final publication is available at

http://doi.org/10.1016/j.nucengdes.2015.10.028

Copyright Elsevier

Additional Information 


\title{
Post test analysis of the ROSA/LSTF and PKL Counterpart test
}

\author{
S. Carlos ${ }^{\mathrm{a}, *}$, A. Querol ${ }^{\mathrm{a}, \mathrm{b}}$, S. Gallardo ${ }^{\mathrm{a}, \mathrm{b}}$, F. Sanchez-Saez ${ }^{\mathrm{a}}$, J.F. Villanueva ${ }^{\mathrm{a}}$, S. Martorella ${ }^{\mathrm{a}}$, G. \\ Verdúa ${ }^{a}$ \\ ${ }^{a}$ Departament d'Enginyeria Química i Nuclear, Universitat Politècnica de València. Camí de Vera, 14. València. Spain. \\ ${ }^{b}$ Instituto de Seguridad Industrial, Radiofísica y Medioambiental, Universitat Politècnica de València. Camí de Vera, \\ 14. València. Spain.
}

\begin{abstract}
Experimental facilities are scaled models of commercial nuclear power plants, and are of great importance to improve nuclear power plants safety. Thus, the results obtained in the experiments undertaken in such facilities are essential to develop and improve the models implemented in the thermal-hydraulic codes, which are used in safety analysis. The experiments and intercomparisons of the simulated results are usually performed in the frame of international programs in which different groups of several countries simulate the behaviour of the plant under the accidental conditions established, using different codes and models. The results obtained are compared and studied to improve the knowledge on codes performance and nuclear safety.

Thus, the Nuclear Energy Agency (NEA), in the nuclear safety work area, auspices several programs which involve experiments in different experimental facilities. Among the experiments proposed in NEA programmes, one on them consisted in performing a counterpart test between ROSA/LSTF and PKL facilities, with the main objetive of determining the effectiveness of late accident managment actions in a small break loss of coolant accident (SBLOCA). This study was proposed as a result of the conclusion obtained by the NEA Working Group on the Analysis and Management of Accidents, which analyzed different installations and observed differences in the measurementes of core exite temperature (CET) and maximum peak cladding temperature (PCT). In particular, the transient consists of a small break loss of coolant accident (SBLOCA) in a hot leg with additional failure of safety systems but with accident management measures (AM), consisting of a fast secondary-side depressurization, activated by the CET. The paper presents the results obtained in the simulations for both installations using TRACE, observing, in general, a good agreement with the experiments. However, ROSA/LSTF calculations underestimated the maximum PCT value, what might be explained by the higher core level predicted in the simulation compared with the experiment. In PKL calculations, PCT maximum value is slightly higher than in the experiment, and the core level predicted is lower. In the comparison of the evolution of both installations a different timing in the transient events is observed, due to the difference in the pressure vessel design. Thus, when PKL vessel is modified with some of the ROSA/LSTF features, the evolution of the new PKL model behaviour is closer the one observed in ROSA/LSTF calculations.
\end{abstract}

Keywords: ROSA, PKL, Core exit temperature, peak cladding temperature, TRACE.

\footnotetext{
${ }^{*}$ Corresponding author

Email addresses: scarlos@iqn.upv.es (S. Carlos ), anquevi@iqn.upv.es (A. Querol), Preprint submitted to Nuclear Engineering and Design
} 
sergalbe@iqn.upv.es (S. Gallardo), frasansa@etsii.upv.es (F. Sanchez-Saez), jovillo0@iqn.upv.es (J.F. Villanueva), smartore@iqn.upv.es (S. Martorell), gverdu@iqn.upv.es (G. Verdú) 


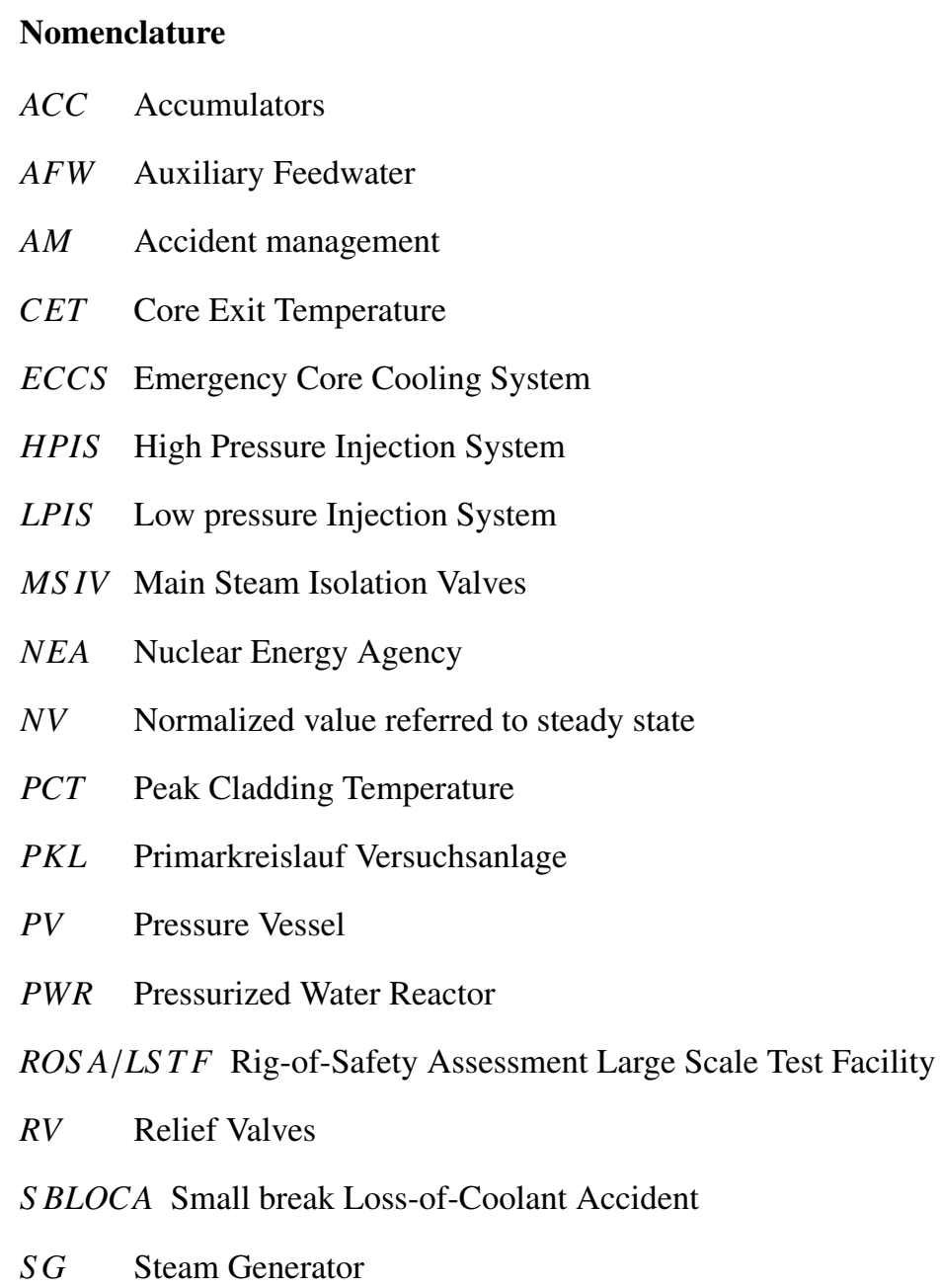

\section{Introduction}

Experimental facilities are of great importance in nuclear safety to improve the knowledge on commercial nuclear power plants behaviour under normal and accidental situations. Thus, it is possible to evaluate the evolution of the main safety variables under an accidental situation and identify generic issues that may affect the safety of nuclear power plants. Such facilities are scaled models of commercial plants, so the lessons learnt from the analysis of the safety variables evolution during the accidental sequence should serve to extend the knowledge on the behaviour of their nuclear power plant of reference, in order to improve nuclear power plants safety. 
Moreover, the results obtained in the experiments undertaken in such facilities are essential to develop and improve the models implemented in the thermal-hydraulic codes. Thus, the data collected in the experiments are necessary in the assessment of the capabilities of thermal-hydraulic codes to reproduce the different physical phenomena that may take place inside the reactor in accidental situations. Such simulations are performed using best estimate thermal-hydraulic codes, as RELAP-5, TRAC, CATHARE, ATHLET or TRACE (Belaid et al. , 2013) (Carlos et al. , 2008) (Freixa J. and Manera A. , 2010). Among these codes, RELAP-5 and TRAC have traditionally been used to reproduce transients of Pressurized Water Reactors (PWR) and Boiling Water Reactors, respectively. Nowadays, TRACE code (TRAC/RELAP Advanced Computational Engine) is being developed to make use of the more favourable characteristics of RELAP-5 and TRAC codes to simulate both, PWR and BWR, technologies.

The experiments and inter-comparisons of the simulated results are usually performed in the frame of international programs in which different groups of several countries simulate the behaviour of the plant under the accidental conditions established, before the experiment, what is known as blind tests, and after the experiment, what are the post test simulations. The results obtained are compared and studied to improve the knowledge on codes performance and nuclear safety. Thus, the Nuclear Energy Agency (NEA), in the nuclear safety work area, auspices several programs which involve experiments in different experimental facilities (Carlos et al. , 2011), (Reventos et al. , 2008), (Gallardo et al. , 2012). Among them, one can find the OECD/NEA Rig-of-safety Assessment (ROSA-2) project and PKL-III project. The first one was focused on the validation of simulation models and methods for the complex phenomena of high-safety relevance for thermal-hydraulic transients in design basis events (DBE) and beyondDBE of light water reactors. To achieve this objective different experiments are performed in the Rig-of-Safety Large Scale Test Facility (ROSA/LSTF) located in Japan, which represents a PWR Westinghouse design. The second programme was mainly focused on investigating safety issues relevant and complex heat transfer mechanisms in current pressurised water reactor PWR plants as well as for new PWR design concepts (Nakamura et al. , 2009) (Umminger et al. , 2012) (Jonnet , 2013). In this programme the experiments were undertaken at Primarkreislauf Versuchsanlage facility (PKL) in Germany which is a scaled model of a Konvoi PWR design.

Among the experiments proposed in those programmes, one of them consisted in performing a counterpart test between both installations. Thus, the experiment is undertaken in the both installations to analyse the effect that different technology and scale may introduce in the evolution of the main safety variables under the same accidental situation. In particular the transient consists of a small break loss of coolant accident (SBLOCA) in a hot leg with additional failure of safety systems but with accident management measures. The counterpart experiment was proposed as a result of the experiments performed by the NEA Working Group on the Analysis and Management of Accidents in different facilities (Toth et al. ,2010). In those experiments a significative difference between CET and PCT evolution was observed in the measurements obtained in all the installations. Thus, as the AM measures are triggered by the CET values but the safety variable normally followed in nuclear safety studies is the PCT, a more detailed study of both variables and the relationship between them was suggested.

Thus, when a SBLOCA occurs the water inventory and pressure of the reactor coolant system decrease and this leads to empty the reactor pressure vessel, and to core uncovering. Therefore, it is necessary the actuation of the safety systems to inject water in the primary circuit, High Pressure Injection System (HPIS) in this case, to maintain the core full of water and cooled. The safety system failures postulated in this transient are no HPIS injection and no automatic secondary-side cooldown. This situation leads to core uncovering and the clad temperature in- 
creases until core-melt scenario if no action is performed. Therefore, it is necessary to explore the Accident Management (AM) measures necessary to prevent this scenario. The AM measures proposed to prevent core melting is a fast secondary-side depressurization, initiated after core uncover to re-establish the steam generators secondary side as heat sink aiming for a fast reduction of the primary pressure, what permits the injection through the accumulators and makes possible the Low Pressure Injection Safety (LPIS) activation. These AM measures are activated by the Core Exit Thermocouples measurements, so the use of Core Exit Temperature (CET) as a valid criterion for the initiation of accident mitigation measures involving emergency operating procedures and/or severe accident management measures has to be assessed, and the efficiency of the accident mitigation measures proposed has to be analysed (Belaid et al. , 2013).

In order to reproduce the same transient in both installations, a conditioning phase is needed to reach in ROSA/LSTF the same working conditions as the ones in PKL. Once this is achieved the break is produced and the physical phenomena occurring in both installations can be compared.

The paper is organized as follows: In section 2, both facilities are presented are described. In section 3 the experiment is explained. The TRACE model developed for each facility is exposed in section 4. In section 5, the results of the transient simulation are discussed. Finally, section 7 presents the main conclusions obtained.

\section{Experimental facilities}

Both facilities are scaled models of different nuclear power plants. Thus, ROSA/LSTF is a scaled model of a Westinghouse and has Tsuruga-2 as reference plant and PKL is a Konvoi type and has as reference plant Phillisburg-2 (Nakamura et al. , 2009) (Umminger et al. , 2012). Both designs present technological differences and also different scale ratios between each technology and their plant of reference, so a brief description of both installations is presented.

\subsection{ROSA/LSTF description}

ROSA/LSTF is a $1 / 48$ volumetrically scaled, full-height, full-pressure simulator of a four loop Westinghouse design pressurized water reactor of $3423 \mathrm{MWt}$ of nominal power. The four primary loops of the reference plant are lumped into two equal volume loops to improve twophase flow simulation during reactor accidents and transients mainly by achieving large diameter horizontal legs. Each loop is sized to conserve the volumetric factor 2/48 and the relation of the length to the square-root of the reference PWR pipe diameter $(L / \sqrt{D})$ to better reproduce the same flow regime transitions in horizontal legs (JAEA, 2003)(Nakamura et al. , 2009).

The primary coolant system consists of the pressure vessel, and two primary loops being the pressurizer located in loop A. Each loop is composed by a primary coolant pump and a steam generator. The U-tube bundles in the steam generators have mostly the same dimensions of the ones in the plant of reference (Nakamura et al. , 2009). The secondary-coolant system consists of a feedwater pump and an auxiliary feedwater pump for each steam generator. The facility also reproduces the plant emergency core cooling system, which includes the high and low pressure injection systems, and two accumulators one in each cold leg. Fig.1 shows a scheme of the ROSA/LSTF installation.

To simulate the core power there are 1008 electrically heated rods, being the maximum core power $10 \mathrm{MW}$, corresponding to $14 \%$ of the reference PWR nominal power. ROSA/LSTF fuel 


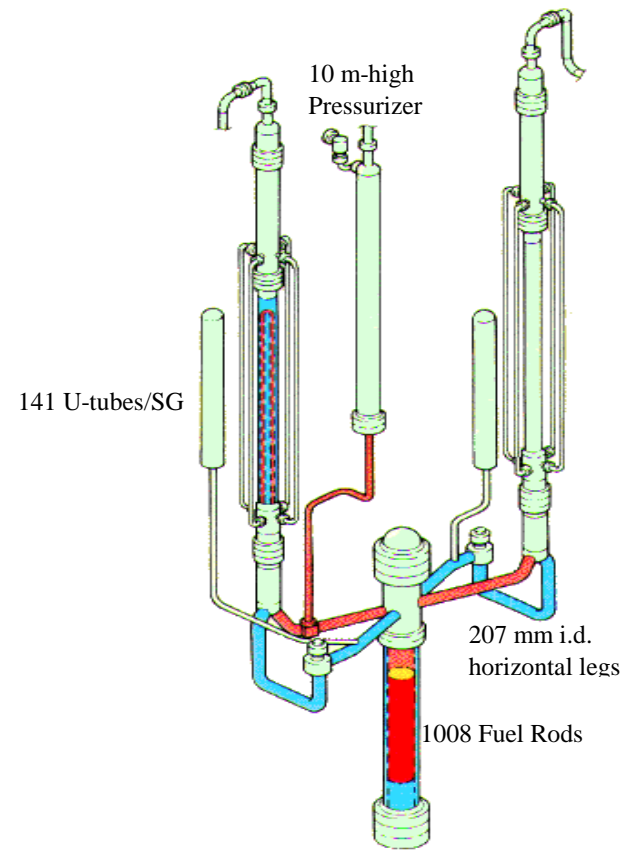

Figure 1: ROSA/LSTF facility.

assembly has mostly the same dimensions as in the reference PWR to preserve the heat transfer characteristics of the core.

\subsection{PKL facility description}

PKL is a full-height, reduced-pressure facility of a four loop Konvoi design pressurized water reactor of $1300 \mathrm{MWe}$ of nominal power. The facility has a scale ratio of $1 / 145$ for volume and power, while all the components height on the primary and secondary side correspond to real plant dimensions. It models the entire primary system and the relevant parts of the secondary side. In order to investigate the influence of non symmetrical boundary conditions on the system behaviour, PKL facility is equipped with four primary loops symmetrically arranged around the reactor pressurized vessel. Each loop contains a reactor coolant pump and a steam generator, and the pressurizer is located in loop 2 (Umminger et al. , 2002).

The facility also models all the important safety and auxiliary systems as eight accumulators, one in each of the hot legs and one in each of the cold legs, four independent injections from the high and low pressure injection system, the residual heat removal system and the pressure control in the presssurizer. Fig. 2 shows a scheme of PKL test facility.

To simulate the core power there are 314 electrically heated rods in the core assembly, being the maximum core power a $10 \%$ of the reference PWR nominal power. 


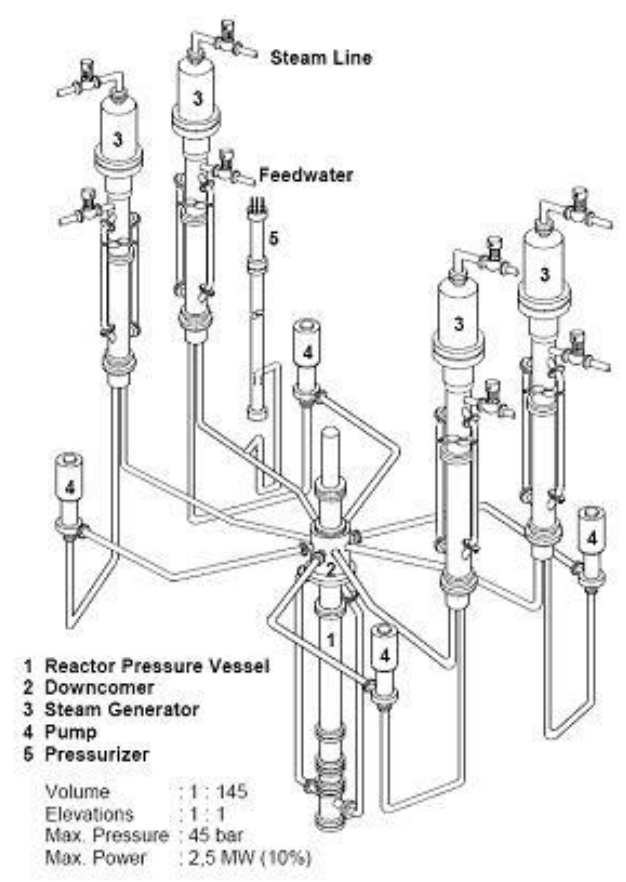

Figure 2: PKL facility.

\section{Transient description}

The SBLOCA is countered by safety injection systems being triggered as soon as the setpoints of the different systems are met, being HPIS the first system being activated. In case of total failure of the HPIS, as postulated in the experiment, the accumulators and the low pressure injection system cannot actuate, as their pressure setpoints are lower than primary pressure when the SBLOCA is detected. In this situation for the most PWR designs, the design-basis course of events foresees a parallel cooldown of the primary side via the steam generators secondary side to reach cold shutdown conditions. This cooldown process may be initiated automatically or manually and may be performed either partially or completely.

Depending on the break size, the primary pressure evolution would lead to a significant core heat-up before the primary pressure drops below the ACCs actuation pressure. For this reason, it is necessary a secondary-side depressurization as accident management (AM) procedure to reduce the primary pressure until the appropriated values to allow ACCs and LPIS safety injections. The signal to trigger the depressurization procedure is the core exit temperature (CET).

The range of operation of both installations is different, so it has been necessary to move ROSA/LSTF and PKL from their normal operational state to similar working condition. The maximum pressure value allowed in PKL is lower that in ROSA/LSTF, so is in this latter installation where there has been necessary to perform several actions to meet a pressure value appropriated for both installations. 


\subsection{ROSA/LSTF Transient description}

The counterpart test corresponds to Test 3 in ROSA/LSTF (JAEA , 2012). This experiment simulates a $1.5 \%$ hot leg SBLOCA in a PWR and it is divided in three phases: high-pressure transient phase, conditioning phase and low-pressure transient phase. Is in the third phase when the evolution of the main safety variables are compared with those obtained from the experiment undertaken in PKL facility. The control logic and sequence of major events for the complete transient are listed in Table 1. All the values presented in this table are normalized to the steady state values.

In the high-pressure phase, the thermal-hydraulic phenomena observed at ROSA/LSTF follow the typical PWR responses during a hot leg SBLOCA until the HPIS coolant injection. The transient starts at time zero with the opening of the break valve in the hot leg of loop B and increasing the rotational speed of the coolant pumps. Few seconds afterwards, the scram signal is generated producing the initiation of the core power decay curve, the primary coolant pumps coast down, a turbine trip, the closure of the Main Steam Isolation Valves (MSIV) and also the stop of Main Feedwater injection. HPI coolant injection starts immediately after the maximum fuel rod surface temperature reaches $1.19 \mathrm{NV}$. This phase finishes when the primary pressure decreases to $0.32 \mathrm{NV}$ and then the break valve is temporarily closed.

In the conditioning phase, the core power is manually changed to a constant value. The primary mass inventory is recovered by continuous HPIS coolant injection into the pressure vessel upper plenum. When the hot leg liquid level recovers up to mid-loop condition, HPIS injection is stopped. Then, the steam generator secondary side depressurization is produced and the AFW injection starts. When the primary pressure reaches $0.26 \mathrm{NV}$, the relieve valves are closed and AFW injection finishes. This phase ends when the primary pressure is around 0.29 NV.

In the low-pressure transient phase, the break valve is re-opened. Due to coolant loss through the break, the core uncovers when core boil-off is produced. Immediately after CET reaches 1.0 $\mathrm{NV}$, the steam generators secondary side depressurization is initiated by fully opening of the RVs as AM action. The AFW injection starts in both steam generators. The ACC system is initiated when the primary pressure is $0.17 \mathrm{NV}$ and ends at $0.08 \mathrm{NV}$. The LPI system is actuated when the pressure vessel lower plenum pressure is $0.06 \mathrm{NV}$. This phase is terminated when continuous core cooling by the LPI system is confirmed.

\subsection{PKL Transient description}

In PKL installation the counterpart test corresponds to the experiment G7.1 (Areva, 2012), and has to be compared with the third phase of ROSA/LSTF experiment, that is the low-pressure pressure phase of the transient. Experiment G7.1 consists of a SBLOCA in the hot leg of the primary side followed by a total failure of the high pressure injection system together with the failure of the automatic steam generator secondary-side cooldown, with fixed power of $1.8 \%$ of the plant of reference scaled nominal power. In such conditions, the accident mitigation procedure proposed is the manual depressurization of the secondary side steam generators, followed by the injection from the accumulators. This accidental sequence was designed to investigate the core heat-up sequence and the effectiveness of depressurization proposed to permit the actuation of ACCs and LPIS. Table 2 presents the sequence of the events produced in PKL facility.

The transient begins when the break in hot leg is produced and the primary circuit empties. Secondary side depressurization is triggered by the core exit temperature (CET) setpoint at 1.0 
Table 1: Control logic and sequence of major events in ROSA/LSTF experiment.

\begin{tabular}{lll}
\hline Phase & Event & Condition \\
\hline High pressure & Break valve open & Time zero \\
transient & Scram signal & Primary pressure set point \\
& Pressurizer heater off & Scram signal or pressurizer liquid level \\
& Core power decay curve simulation & Scram signal \\
& Initiation of Primary Coolant Pump coastdown & Scram signal \\
& Turbine trip & Scram signal \\
& Closure of main steam valves & Scram signal \\
& Termination of SG Main Feedwater & Scram signal \\
& Start of HPIS & PCT = 1.19NV \\
& Break closure & Primary pressure 0.32NV \\
& Constant core power & Break closure \\
& End of HPIS & Hot leg level at mid-loop \\
& Start of SG secondary-side depressurization & End of HPIS \\
Low pressure & Bnd of SG secondary-side depressurization & Primary pressure 0.26NV \\
& Break valve re-open & Primary pressure 0.29NV \\
& SG secondary-side depressurization & $C E T=1.0 N V$ \\
& Initiation of auxiliary feedwater & Initiation of AM action \\
& Initiation of ACC system & Primary pressure set point \\
& Termination of ACC system & Primary pressure set point \\
& Initiation of LPI system & Pressure vessel lower plenum pressure set point \\
\hline
\end{tabular}


Table 2: Control sequence of major events in PKL experiment.

\begin{tabular}{ll}
\hline Event & Condition \\
\hline Break valve open & Start of the transient \\
SG secondary-side depressurization & CET 350 C MIRAR CET $=1.0 \mathrm{NV}$ \\
Initiation of ACC system & MIRAR pprim $=26.6$ bar Primary pressure set point \\
Termination of ACC system & MIRAR 10.0 bar Primary pressure set point \\
Initiation of LPI system & MIRAR 7.7 bar Pressure vessel lower plenum pressure set point \\
\hline
\end{tabular}

NV. As in PKL all four SG are connected, the secondary side depressurization is homogeneous for all $\mathrm{SG}$, and permits to reduce the primary pressure to reach the accumulators pressure set point, so this system injects water in the reactor coolant line and, later on, the primary pressure reaches LPIS activation set point and coolant injection is produced.

\section{TRACE models}

In both installations the transient has been simulated using the TRACE- 5 V2 thermal-hydraulic code, as it is being developed to make use of the more favourable characteristics of RELAP-5 and TRAC codes to simulate both, PWR and BWR, technologies. TRACE code analyses transient and steady-state neutronic-thermal-hydraulic behaviour in light water reactors. In fact, TRACE has been designed to perform best-estimate analyses of loss-of-coolant accidents (LOCAs), operational transients, and other accident scenarios in pressurized light-water reactors (PWRs) and boiling light-water reactors (BWRs), and it can also model phenomena occurring in experimental facilities designed to simulate transients in reactor systems (USNRC, 2010a) (USNRC, 2010b).

\subsection{ROSA/LSTF Model}

ROSA/LSTF has been modelled using 97 hydraulic components (11 BREAKs, 12 FILLs, 25 PIPEs, 2 PUMPs, 1 PRIZER, 26 TEEs, 19 VALVEs and 1 VESSEL) (USNRC, 2010a) (USNRC , 2010b). Heat transfer between primary and secondary side, pressurizer heaters and heat losses have been performed by using 50 Heat Structures (HTSTR) components. Cylindrical-shape geometry has been used to best fit heat transmission. The power supplied to the vessel from 1008 fuel elements, presents in the LSTF, has been simulated using a POWER component. Figure 3 shows the nodalization of the model using the Symbolic Nuclear Analysis Package software (SNAP) (Applied Programming Technology, 2012).

In order to model the pressure vessel, a VESSEL component has been considered. A nodalization of 20 axial levels, 4 radial rings and 10 azimuthal sectors is a quite accurate model of the real pressurized vessel. For each axial level, volume and effective flow area fractions have been set according to technical specifications provided by the organization (JAEA , 2003). Axial levels 1 and 2 simulate the lower plenum. The active core is located between levels 3 and 11 . Level 12 simulates the upper core plate. Levels 13 to 16 characterize the vessel upper plenum. The upper core support plate is located in level 17. Finally, upper head is defined between levels 18 to 20. The VESSEL is connected to different 1D components: 8 Control Rod Guide Tubes (CRGT), hot leg A and B (level 15), cold leg A and B (level 15) and a bypass channel (level 14). 
Control rod guide tubes have been simulated by PIPEs components, connecting levels 14 and 19 and allowing the flow between upper head and upper plenum.

The power ratio in the axial direction presents a peaking factor of 1.495 . The radial power profile is divided into three power zones using the first three radial rings. Depending on the radial ring, different peaking factors have been considered ( 0.66 in ring $1,1.51$ in ring 2 and 1.0 in ring 3). A POWER component represents the power supplied by each HTSTR transferred to the 3D-VESSEL through 30 HTSTRs, which simulate the 1008 fuel assemblies presents in the ROSA/LSTF reactor core. These fuel assemblies were distributed into the 3 rings: 154 fuel assemblies in ring 1, 356 in ring 2 and 498 in ring 3 . The number of fuel rod components associated with each heat structure has been determined from the technical documentation given, taking into account the distribution of fuel rod elements in the vessel.

A detailed model of SG (geometry and thermal features) has been developed, due to the fact that TRACE-5 does not include any pre-determined steam generator component. Both boiler and downcomer components of secondary side have been modeled by TEEs components. Each SG has 141 U-tubes, which are simulated by 3 PIPE components depending on the average length of real U-tubes and heat transfer features. Heat transfer between primary and secondary sides has been performed by using HTSTR components. Inner and outer surface boundary conditions for each axial level have been set to couple HTSTR component to hydro-components (primary and secondary fluids).

HPIS and LPIS have been simulated using FILL components. The ACC are represented by two PIPE components. For this transient, HPI is connected to pressure vessel upper plenum.

The SBLOCA has been simulated by means of a VALVE component connected to a BREAK component in order to establish the boundary conditions. The break, specified in Test 3 (JAEA, 2012), is located on the hot leg of loop B downwards orientation.

\subsection{PKL Model}

The PKL model used consists of 136 hydraulic volumes, including two 3D VESSEL components, 5 BREAKs, 16 FILLs, 84 PIPEs, 4 PUMPs, 21 VALVEs and 37 heat structures. Fig. 4 presents a SNAP view of the primary and secondary circuit (Applied Programming Technology, 2012). The most interesting feature in this model is the reactor pressure vessel nodalization, that has been modelled as a combination of two VESSEL hydraulic components: core vessel and downcomer vessel, as shown in Fig. 4. Using this nodalization the coolant paths inside the vessel are closer to the real ones. The core vessel models the lower and upper plenums, the core, and the head of the PKL reactor pressure vessel, while the downcomer vessel represents the part of the reactor pressure vessel downcomer, and are connected by the two external downcomer pipes and by the four upper head downcomer by passes.

The core vessel has been divided in 19 axial levels, 1 radial ring and 2 azimuthal sectors. In the axial direction, the active core is modeled by 7 levels ( 6 to 12), and the hot legs are connected at level 15 in radial direction. The downcomer vessel has been divided in 5 axial levels, 3 radial levels and 2 azimuthal sectors. It is modelled as an annulus so the most internal radial level does not belong to the model. The second radial ring connects the vessel with the reactor coolant line cold legs and the third ring connects, in axial direction, to the downcomer pipes, which in turn are connected to the lower plenum, represented by the lowers levels of the core vessel. For both vessels, each axial level, volume and effective flow area fractions have been set according to PKL technical specifications provided by the organization (Areva, 2012). 


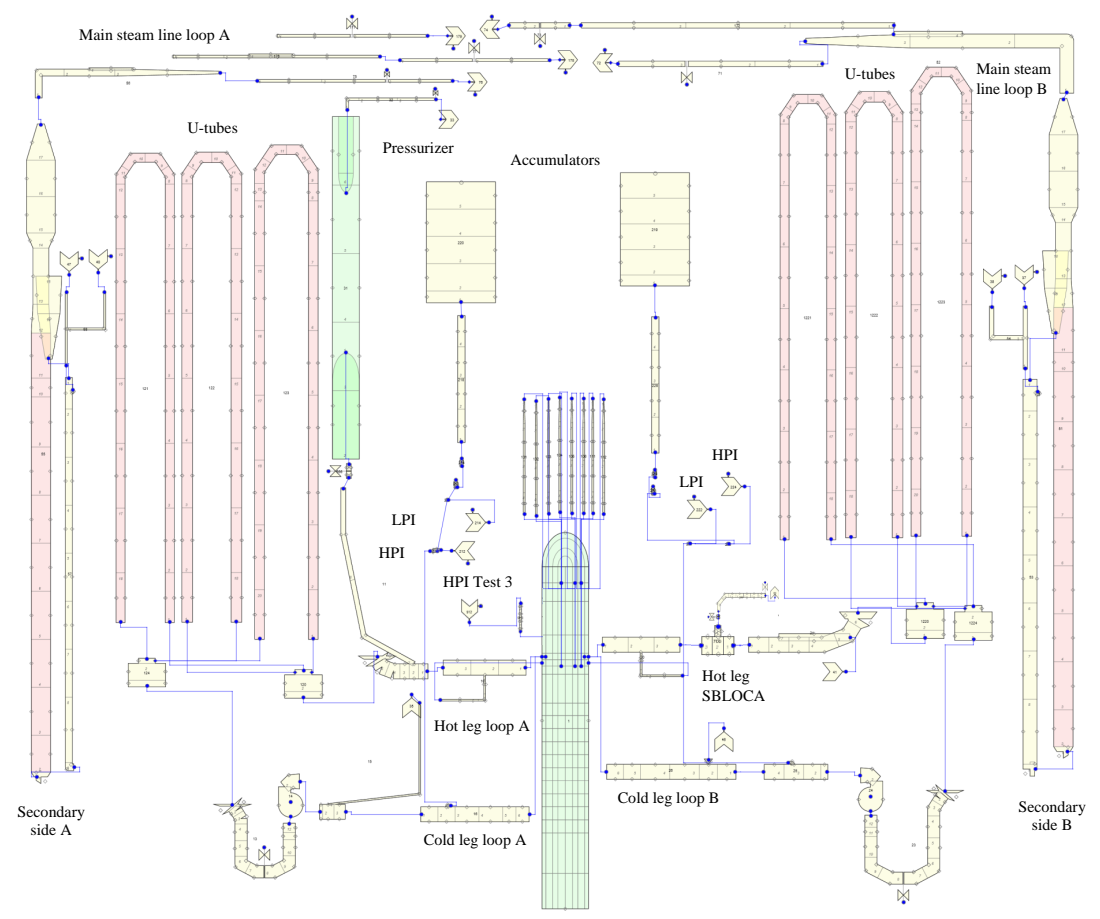

Figure 3: TRACE model for ROSA/LSTF facility.

The four primary loops are modelled with a pump and a steam generator in each loop using PIPE and PUMP components. The U-tubes of the steam generators are lumped into three PIPE components of different heights. The heat transfer between the primary and secondary systems is simulated using three heat structures, one for each of the three pipes that simulate the steam generators U-tubes.

The injections from the accumulators performed at the transient have been simulated using a PIPE component connected to the loop by a VALVE. The locations of the injections from the accumulators are shown in Fig 4. A LPIS injection has been simulated in each cold leg by using FILL components connected with the loops. Finally, the SB-LOCA has been simulated with a BREAK component connected to the hot leg 1.

The nodalization of the steam generators secondary side is also presented in Fig. 4. The four steam generators are connected through their corresponding relieve valves to simulate depressurization control considered as accident mitigation measure. In the nodalization the main steam valves have been also modelled. 


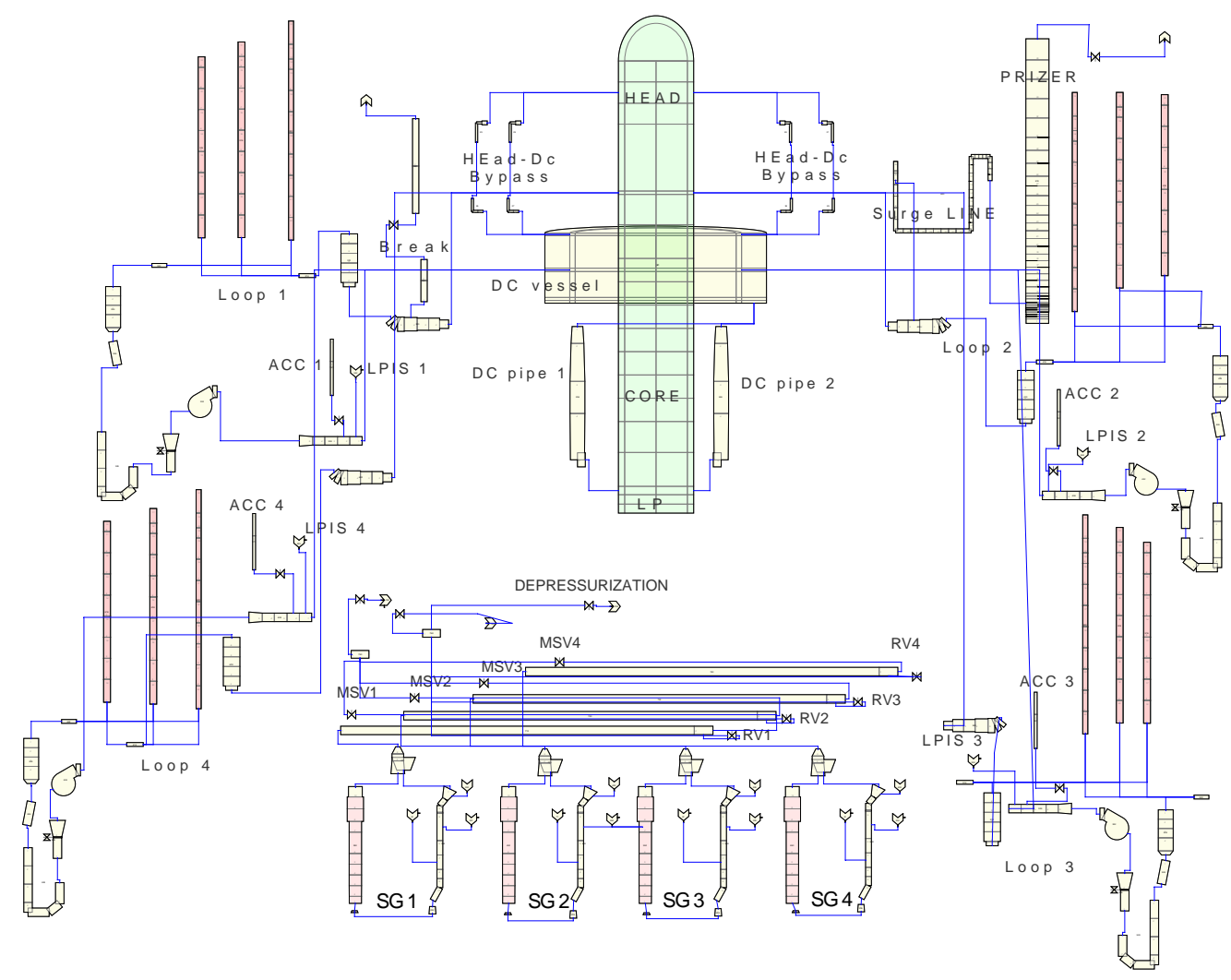

Figure 4: TRACE model for PKL primary circuit.

\section{Simulation results}

\subsection{ROSA/LSTF results}

In order to compare the behaviour of both facilities, the experiment in ROSA/LSTF facility has been divided in three phases: High pressure transient, conditioning phase and low pressure transient. This later phase is the one compared with PKL transient. Thus, Table 3, Table 4 and Table 5 present the chronological sequence of events during the transient and the comparison between the experiment and TRACE results, for the high pressure transient, conditioning phase and low pressure transient, respectively. Results presented in this section have been normalized to the steady state value in each graph.

The comparison between experimental data and TRACE results in ROSA/LSTF is presented through several graphs of the most important variables. Specifically, Figure 5 shows (a) the system pressures, (b) the mass flow rate through the break, (c) the pressure vessel liquid levels and (d) the Peak Cladding Temperature (PCT) together with the Core Exit Temperature (CET) for each phase of the transient. 
Table 3: ROSA/LSTF high pressure transient. Chronological sequence of events.

\begin{tabular}{lcc}
\hline Event & $\begin{array}{c}\text { Experiment } \\
\text { time (s) }\end{array}$ & $\begin{array}{c}\text { TRACE-5 } \\
\text { time (s) }\end{array}$ \\
\hline Break valve open & 0 & 0 \\
Scram signal & 29 & 32 \\
Closure of SG MSIVs & 32 & 33 \\
Initiation of coastdown of primary coolant pumps & 33 & 35 \\
Termination of SG main feedwater & 34 & 33 \\
SI signal & 37 & 43 \\
Initiation of core power decay & 50 & 47 \\
Primary coolant pumps stopped & 281 & 280 \\
Primary pressure became lower than SG secondary side pressure & 1310 & 1317 \\
Start of increase in fuel rod surface temperature & 1595 & 1680 \\
Maximum fuel rod surface temperature reached 750 K & 1840 & 1796 \\
Initiation of HPI into PV upper plenum & 1844 & 1796 \\
\hline
\end{tabular}

Table 4: ROSA/LSTF conditioning phase. Chronological sequence of events.

\begin{tabular}{lcc}
\hline Event & $\begin{array}{c}\text { Experiment } \\
\text { time (s) }\end{array}$ & $\begin{array}{c}\text { TRACE5 } \\
\text { time (s) }\end{array}$ \\
\hline Break valve closure & 2172 & 2113 \\
Manual change of core power to constant value & 2215 & 2500 \\
Termination of HPI system into PV upper plenum & 2852 & 2880 \\
Initiation of SG secondary-side depressurization by fully opening RVs in both loops & 2880 & 2893 \\
Initiation of AFW in both loops & 2900 & 2893 \\
Termination of SG secondary-side depressurization & 3028 & 2959 \\
Termination of AFW in both loops & 3055 & 2959 \\
\hline
\end{tabular}


Table 5: ROSA/LSTF low pressure phase. Chronological sequence of events.

\begin{tabular}{lcc}
\hline Event & $\begin{array}{c}\text { Experiment } \\
\text { time (s) }\end{array}$ & $\begin{array}{c}\text { TRACE5 } \\
\text { time (s) }\end{array}$ \\
\hline Break valve open again & 3323 & 3303 \\
Start of increase in fuel rod surface temperature & 3983 & 4203 \\
Primary pressure became lower than SG secondary side pressure & 4105 & 4250 \\
Core exit temperature setpoint = 623 K & 4390 & 4507 \\
Initiation of SG secondary-side depressurization & 4394 & 4519 \\
by fully opening RVs in both loops as AM action & & \\
Initiation of AFW in both loops & 4410 & 4519 \\
Maximum fuel rod surface temperature & 4413 & 4545 \\
Initiation of ACC system in both loops & 4500 & 4590 \\
Termination of ACC system in both loops & 4829 & 4786 \\
Initiation of LPI system in both loops & 5003 & 4830 \\
\hline
\end{tabular}

In the high pressure transient phase (until $2170 \mathrm{~s}$ ), the primary pressure starts to decrease at time zero when the break valve is opened causing the scram signal (see Figure 5(a)). It implies the closure of the MSIVs and the primary coolant pumps coastdown. The steam generator secondary side pressure increases rapidly after the closure of MSIVs. From this moment on, the steam generator secondary side pressure starts to fluctuate by means of opening and closing the relief valves. The primary pressure becomes lower than the secondary one at about $1250 \mathrm{~s}$. When the primary pressure reaches $0.32 \mathrm{NV}$, the break valve closes and this transient phase ends. In general, TRACE is able to reproduce the behaviour of the system pressures during this transient phase, although the pressure drop in the primary pressure is faster in the experiment. Thus, from $1250 \mathrm{~s}$ until the activation of high pressure injection system, TRACE predicted values for primary pressure are higher than the experimental data. However, secondary side pressure calculations are close to the experimental values during all the phase.

At the start of transient the calculated mass flow rate through the break presents a sharp decrease, faster in the calculations than in the experiment, when the fluid turns from single-phase liquid to two-phase flow (see Figure 5(b)). When the primary pressure becomes lower than the secondary one, the break flow turns from two-phase flow to single-phase vapour. Both changes of regime are well reproduced with TRACE. However, during the two-phase flow (between 250 and $1000 \mathrm{~s}$ ), TRACE mass flow rate prediction is higher than the experiment.

Regarding the pressure vessel liquid levels, during the first $800 \mathrm{~s}$ the downcomer is gradually emptied (see Figure 5(c)). After that, downcomer liquid level is maintained until $1250 \mathrm{~s}$ when it starts to drop again. The calculations do not reproduce the first decrease in the downcomer level, and until $1250 \mathrm{~s}$ the calculated level is higher than the experimental level. However, at this moment TRACE predicts a decrease in the level up to a value slightly lower than the one observed in the experiment.

The core and upper plenum liquid levels fall during the first $500 \mathrm{~s}$. The upper plenum is emptied at $1500 \mathrm{~s}$, while the core liquid level starts to drop at about $1550 \mathrm{~s}$ by boil-off. Core uncover is produced about $600 \mathrm{~s}$ after the primary pressure becomes lower than the secondary one, as secondary side heat sink is lost. Calculated and experimental evolutions of core and 
upper plenum levels are quite similar, however core level is slightly higher in the calculation. At $1550 \mathrm{~s}$ downcomer liquid level reaches about $1 / 3$ of its total height and the upper plenum remains empty, in both, experiment and calculation.

CET and PCT excursions in the high pressure phase start at $1700 \mathrm{~s}$ (see Figure 5(d)). When the maximum PCT reaches $750 \mathrm{~K}$ (at 1840 s), the HPI system starts to inject coolant into the pressure vessel upper plenum and the water level is recovered. The evolution of PCT and CET temperatures are well reproduced with TRACE, as the time of temperature raise and the values reached are quite similar.

In the conditioning phase (from $2170 \mathrm{~s}$ to $3400 \mathrm{~s}$ ), the core power is fixed to a constant value until the end of the transient. Furthermore, the break valve is closed and the HPI system injects coolant into the pressure vessel upper plenum. In these conditions, the primary pressure increases up to about $0.42 \mathrm{NV}$ at $2900 \mathrm{~s}$, such behaviour is well predicted by TRACE. At this time, the hot leg levels reach mid-loop and the HPIS injection ends. A steam generator secondary side depressurization is produced and the AFW injection starts. Following the secondary pressure drop, the primary pressure decreases until around $0.25 \mathrm{NV}$. At this pressure, depressurization is finished, the RVs are closed and the AFW injection ends. In Figure 5(a), it is observed that TRACE depressurization is faster that in the experiment. Once the RVs close, the system pressures increase until around 0.29 NV and this transient phase ends. During this phase, HPIS injection produces core quenching, the downcomer recovers $1 / 3$ of its liquid level and the upper plenum reaches half its level. The pressure vessel levels increase predicted by TRACE fit very well the experimental results during this transient phase.

At the beginning of low pressure phase transient, ROSA/LSTF pressure conditions are similar to PKL ones and the results obtained in this phase can be compared with PKL results. The low-pressure transient phase starts by opening the break valve at $3400 \mathrm{~s}$. The primary pressure becomes lower than the secondary one at about $4250 \mathrm{~s}$ and $150 \mathrm{~s}$ after, core boil-off is produced. When the CET reaches $623 \mathrm{~K}$, the AM action is activated. The steam generator secondary side depressurization is initiated by fully opening of the relief valves and the AFW injection starts. At around $4400 \mathrm{~s}$, the primary pressure starts to decrease following the secondary one (see Figure 5(a)). As occurred in the conditioning phase, TRACE depressurization is faster than in the experiment. When primary pressure decreases, ACC injection set points are met, and injection is produced. After that, primary pressure continues to fall reaching the LPI pressure set point. This phase is finished when continuous core cooling is confirmed with the LPI system actuation.

In this phase, the core liquid level, see Figure 5(c), starts to fall from $3900 \mathrm{~s}$ reaching the core boil-off at $4400 \mathrm{~s}$. Then, the core starts to recover due to depressurization and temporarily decreases again due to the steam condensation produced by the ACC coolant injection into the cold legs. From this moment on, the core is refilled until the end of the transient.

At $3484 \mathrm{~s}$ break opens and counterpart test transient begins. At this time, experimental and TRACE calculations of the total mass inventory inside the vessel is the same. However, the distribution of coolant inventory presents a discrepancy. Thus, while in the upper plenum and dowcomer vessel the values of coolant mass predicted by the code are similar to the experiment, in the vessel core the code predicts an excess of coolant, and in the upper head the mass is underestimated. Thus, due to the different distribution of coolant between the core and the upper head, TRACE calculation overestimates core level values, what means that more coolant mass remains in the core, influencing the evolution of CET and PCT. Moreover, TRACE5 choke models only allow adjusting the liquid single phase and mixture coefficients, but there is no coefficient for single phase vapour. During the first seconds after the break opening the mass flow through the 
Table 6: PKL transient. Chronological sequence of events.

\begin{tabular}{lcc}
\hline Event & $\begin{array}{c}\text { Experiment } \\
\text { time (s) }\end{array}$ & $\begin{array}{c}\text { TRACE5 } \\
\text { time (s) }\end{array}$ \\
\hline Break valve open & 0 & 0 \\
Start of increase in fuel rod surface temperature & 937 & 923 \\
Primary pressure became lower than SG secondary side pressure & 1000 & 1000 \\
Core exit temperature setpoint = 623 K & 1345 & 1388 \\
Initiation of SG secondary-side depressurization as AM action & 1320 & 1286 \\
Initiation of AFW in all loops & 1470 & 1480 \\
Maximum fuel rod surface temperature & 1425 & 1444 \\
Initiation of ACC system in all loops & 1500 & 1418 \\
Termination of ACC system in all loops & 1875 & 1727 \\
Initiation of LPI system in all loops & 2060 & 1936 \\
End of transient & 4300 & 4300 \\
\hline
\end{tabular}

break is a two phase mixture, but it becomes single phase vapour in a few seconds. Other authors, as for example in (Freixa J. et al , 2015), have obtained better results in the pressure vessel levels prediction using an in-house version of TRACE5 capable of considering a specific coefficient for single phase vapor.

When core boil-off starts, CET and PCT excursions are produced and then they decrease due to the coolant injection from ACC. The rise in CET and PCT is delayed in TRACE calculation, in agreement with core level evolution, and the maximum PCT value reached is lower than the experimental one. As depressurization, performed as an accident management measure to maintain PCT under safe values. is triggered by the CET value, it is important to analyse the relationship between these two parameters, shown in Fig. 6. In this Figure, it is observed that for low CET values the calculation predicts a higher value for PCT that the one observed in the experiment, but as CET rises the predicted PCT value is lower than the experimental one. So, the calculation does not provide conservative values of PCT for high values of CET.

\subsection{PKL results}

The transient undertaken in PKL facility corresponds to the third phase of the ROSA/LSTF transient, as PKL facility can not work at the pressures reached in the first and second phases of the ROSA/LSTF transient. Table 6 presents the timing of the different events measured in the experiment compared with the values predicted by TRACE. In general, a good agreement between the experiment and the calculation is observed. In fact, the greatest deviation is observed at the time at which the injection from accumulators finishes, as TRACE is $148 \mathrm{~s}$ advanced to the experimental data. The calculations also predict an advancement of $124 \mathrm{~s}$ in the injection from the LPIS.

The evolution of the most important variables is presented in Fig. 7 and, in general, a good agreement between the experimental data and TRACE calculations in the evolution of the main plant variables is observed. The break is produced at the start of the transient and coolant flows 
out through the break, as shown in Fig. 7(b), where TRACE and experimental values are presented. Differences between predicted and experimental values are found from the break opening to $200 \mathrm{~s}$, where the flow predicted is higher than the experimental value, and at $2500 \mathrm{~s}$ where the experimental mass flow through the break presents an increase not reproduced by TRACE. As mass flows out through the break, the coolant inventory in the primary system is reduced. The initiating event considered is a SBLOCA, so the reduction of coolant in the primary system is not evidenced immediately inside the reactor pressure vessel. Thus, it is not until $500 \mathrm{~s}$ in the downcomer, and around $750 \mathrm{~s}$ in the core when the reduction in the coolant due to both, break flow and evaporation is detected and the water level decreases, as shown in Fig. 7(c). In the coolant inventory reduction, a delay in the TRACE calculation to predict the decrease in the downcomer level is observed. Thus, in the experimental data such decrease is observed between $250 \mathrm{~s}$ and $500 \mathrm{~s}$, which is not reproduced in TRACE (see Fig. 7(c)). However, from around 600 $\mathrm{s}$ to $800 \mathrm{~s}$ of the start of the transient, the experimental level is kept constant while a decrease in the TRACE calculations is observed, and at $1000 \mathrm{~s}$ both values met at $0.5 \mathrm{NV}$, and a continuous decrease is observed. A difference in the core level is observed from the start of the transient being the experiment at $0.6 \mathrm{NV}$ while TRACE predicts a value of $0.65 \mathrm{NV}$. However, the core level decrease is advanced and faster in the calculations than in the experiment, so the minimum level reached in the core in the simulation is below the experimental value.

The pressures in the primary and secondary systems are kept relatively constant at $0.3 \mathrm{NV}$, from the start of the transient until $1000 \mathrm{~s}$ for both, experimental and TRACE calculations, as shown in Fig. 7(a). At this time, a decrease in the primary pressure is observed due to the mass break discharge. The calculation predicts a faster decrease in the primary pressure compared with the experimental values. Due to this effect, the primary pressure falls below the secondary pressure and the heat sink is lost.

Regarding the level in the core vessel, TRACE calculations predict a higher level during the first $750 \mathrm{~s}$ of the transient. Around $750 \mathrm{~s}$ the core level starts to decrease, due to the loss of coolant through the break and the vapour formation in the core, see Fig. 7(d), leading to core uncover. The level decreases slightly faster than in the experiment and reaches a minimum value at $1500 \mathrm{~s}$. At $1400 \mathrm{~s}$ approximately, an increase in the core level is observed in the experiment, the coolant entering the core comes from the downcomer, as can be observed in Fig. 7(c). This effect is not reproduced by TRACE calculations, as the downcomer level predicted at $1400 \mathrm{~s}$ is lower than in the experiment so, the amount of water entering the core is not enough to reproduce the core level increase. Thus, the discrepancy in the levels inside the vessel observed in Fig. 7(c) and Fig. 7(d) is caused by the different coolant inventory distribution observed from the start of the transient. At $1500 \mathrm{~s}$. the accumulators injection is produced, and the core level presents a sharp increase and the consequent drop in the PCT values (see Fig. 7(d) and Fig. 7(e)). This phenomenon is advanced in the calculations because the signal that starts safety injection is the primary pressure and, as shown in Fig. 7(a), the calculated pressure is lower than in the experiment, so the set point is reached earlier. In fact the injection from accumulators began at $1418 \mathrm{~s}$ in the calculation while in the experiment is al $1500 \mathrm{~s}$ (see Table 6).

The decrease in the core level causes the increase in the cladding and coolant temperatures as observed in Fig. 7(e), in which PCT and CET temperatures are represented. PCT and CET evolutions are well reproduced by TRACE, although the CET is slightly higher in TRACE calculation than in the experimental data and the start of the rise is advanced $50 \mathrm{~s}$. When CET reaches the set point, secondary side depressurization is initiated (see Fig. 7(a) and Fig. 7(e)), as an AM measure to decrease the primary system pressure until the accumulators pressure set point is met. In TRACE calculations, the depressurization is advanced $34 \mathrm{~s}$ from the experiment, see Table 6 , 
as the signal that triggers this action is the CET value which is advanced from the experimental measurements. The accumulator injection begins when the primary pressure is lower than 0.15 $\mathrm{NV}$ at $1418 \mathrm{~s}$ in the TRACE calculations and advanced $82 \mathrm{~s}$ from the experimental measures as exposed in Table 6. After the injection from the accumulators, the only heat sink available is the steam discharge through the break, until primary pressure reaches LPIS activation set point, and injects water in all four cold legs. This occurs at $1936 \mathrm{~s}$ for TRACE calculations which is advanced again from the experiment in $124 \mathrm{~s}$. As in the ROSA/LSTF installation in PKL the depressurization is an accident management measure to maintain PCT under safe values, and is triggered by the CET, so it is important to analyse the relationship between these two parameters in PKL facility. Fig. 8 shows the CET vs PCT diagram and it is observed that in the calculations the PCT predicted by a certain CET value is always lower that the PCT experimental value reached. So, TRACE calculation does not provide conservative values of PCT for any CET value. 
a)

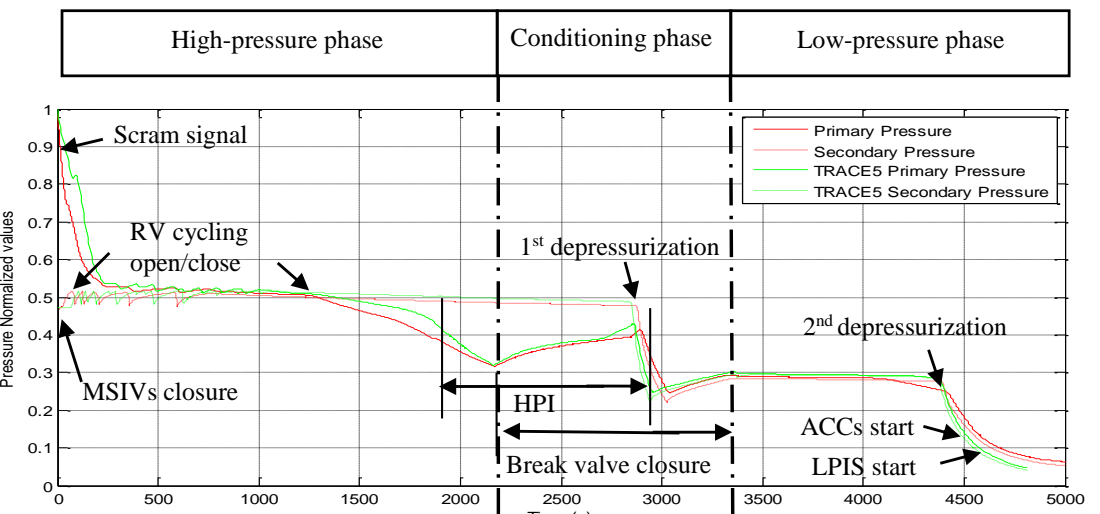

b)

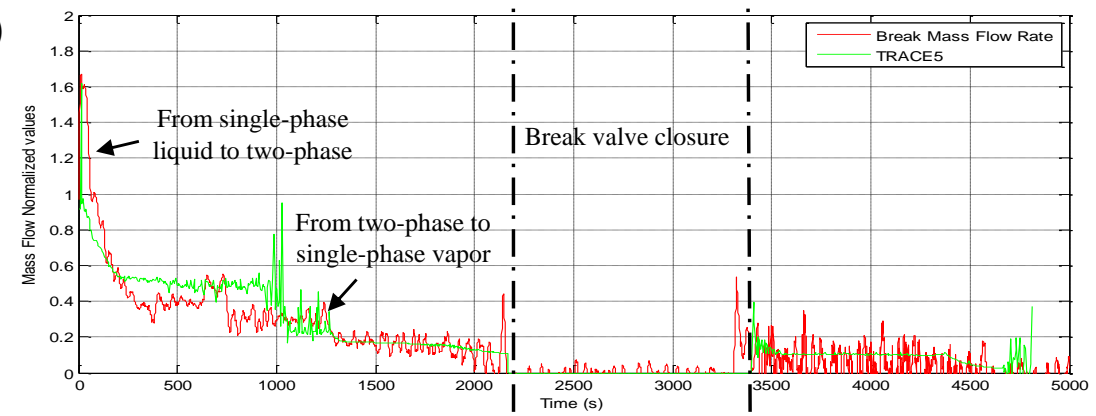

c)

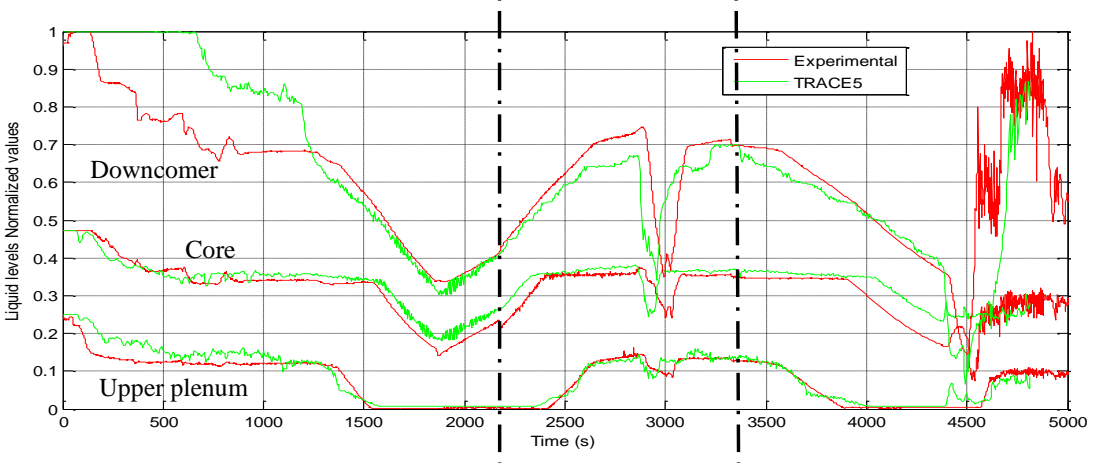

d)

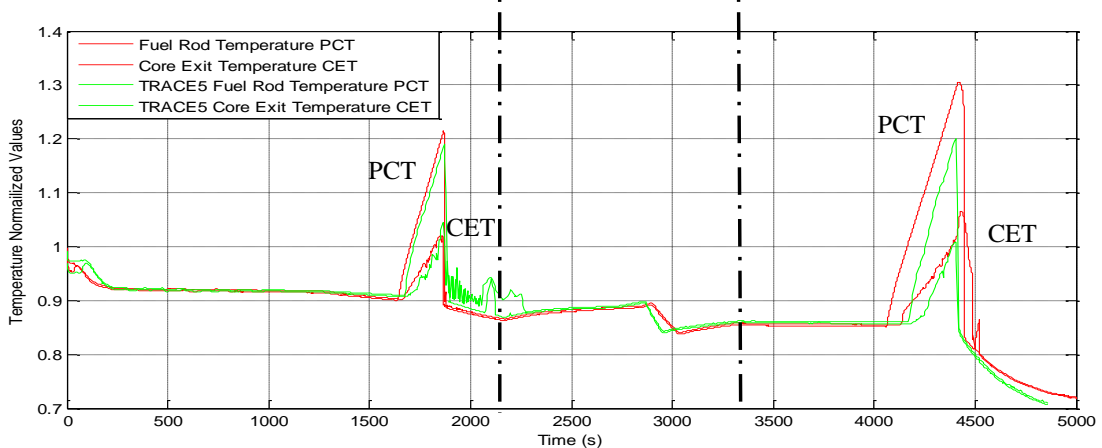

Figure 5: Experimental and simulated ROSA/LSTF results2Q) Primary and secondary pressure, b) Break mass flow rate, c) Pressure vessel liquid levels and d) PCT and CET. 


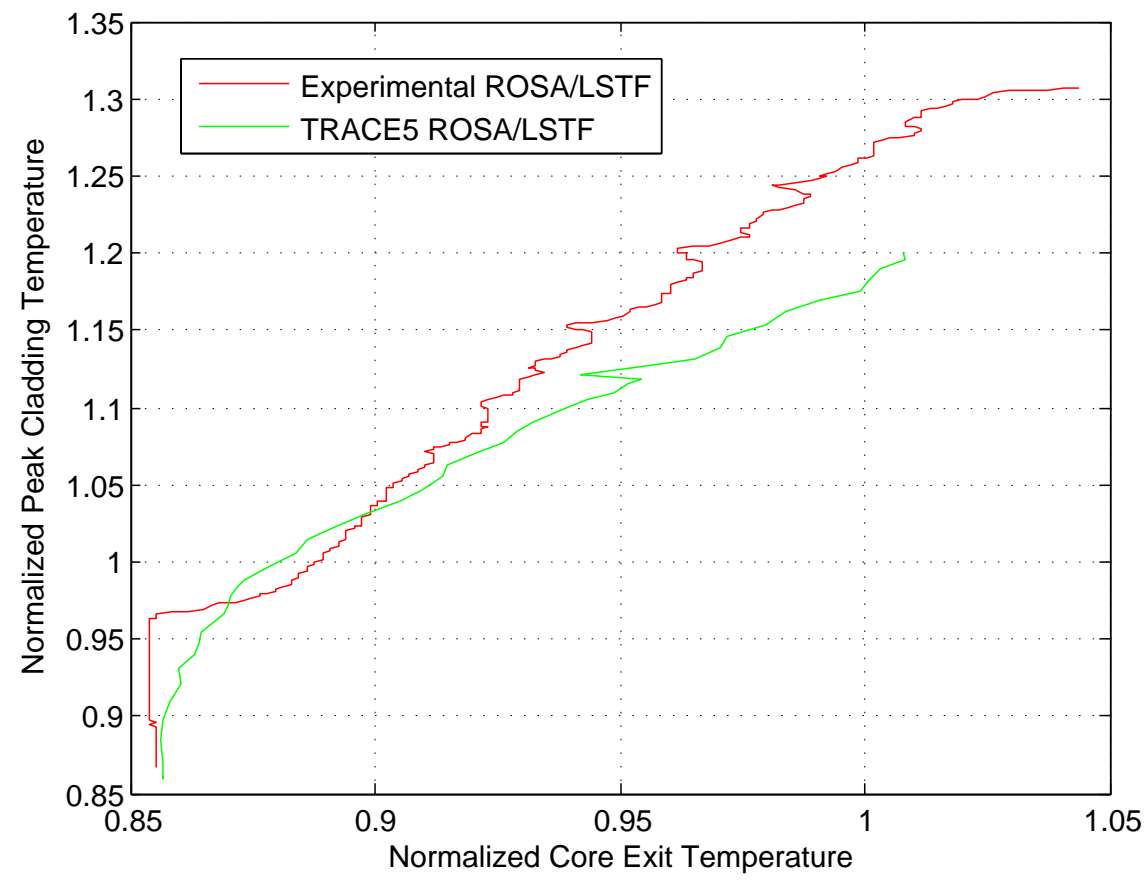

Figure 6: CET vs PCT relationship at ROSA/LSTF. 

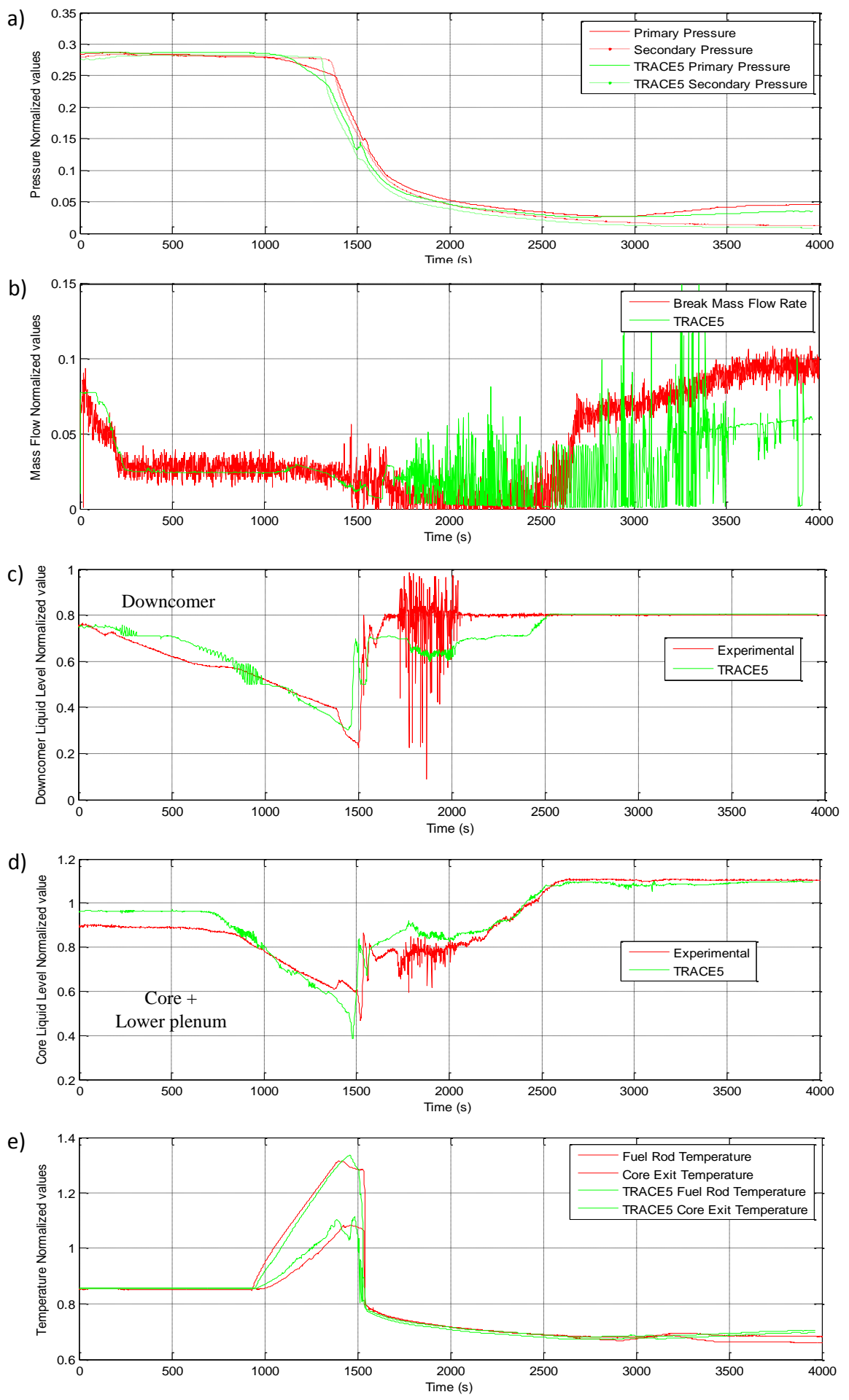

Figure 7: Experimental and simulated PKL results: a) Pfifnary and secondary pressure, b) Break mass flow rate, c) Downcomer liquid level, d) Core liquid level, and e) PCT and CET. 


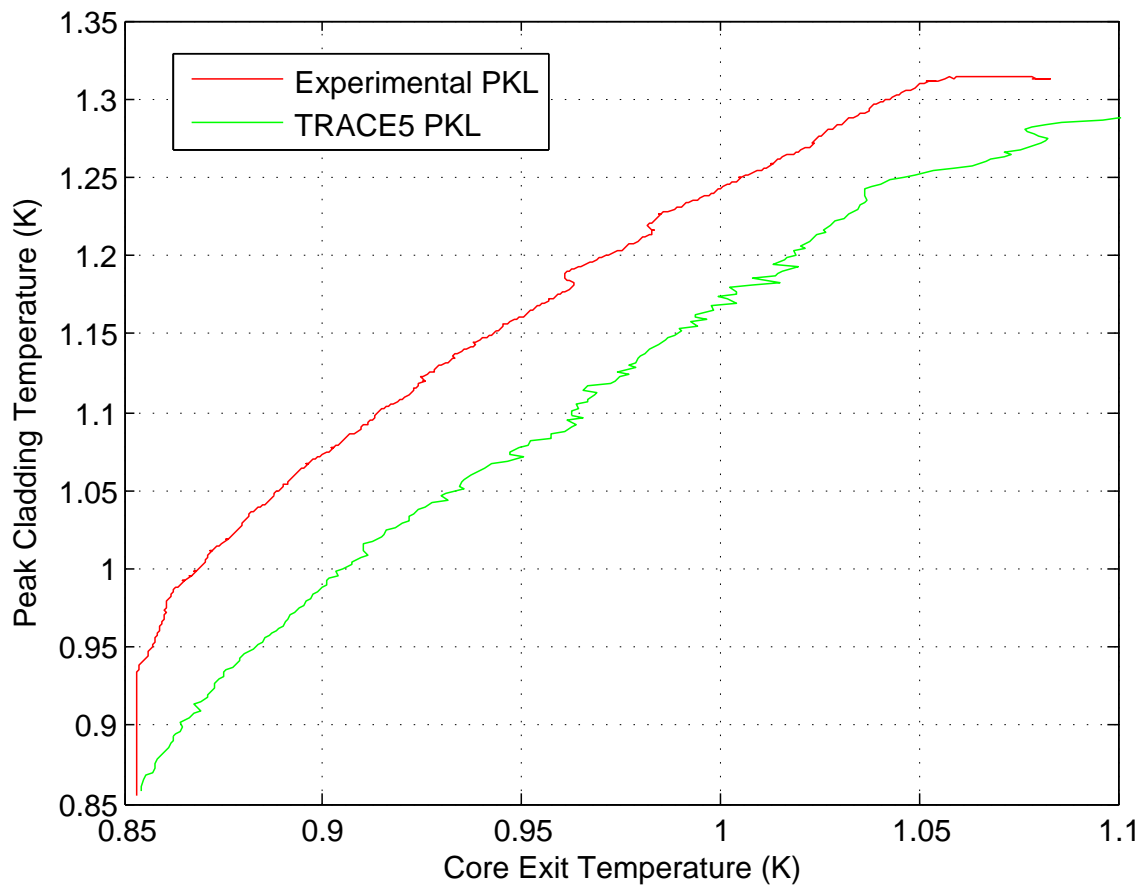

Figure 8: CET vs PCT relationship at PKL. 


\section{ROSA/LSTF and PKL comparison}

The counterpart transient was develop to assess the efficiency of the accident management measures in both facilities. That is, to study if PKL and ROSA/LSTF, which are facilities of different design and scaling, will present a similar evolution when the same accident management procedure is followed (Toth et al. , 2010). However, in the experimental data of both facilities some differences are found, for example in ROSA/LSTF the increase in the PCT is faster and occurs earlier than in the PKL experiment (see Fig. 5(d) and 7(e)).

The differences found in the evolution of the main variables for both installations can be related with the different scaling and/or with the difference in the technology (Querol et al. , 2014), (Martinez-Quiroga et al. , 2014), (Toth et al. , 2010). Focusing on this latter aspect, the reactor pressure vessel design can greatly influence the evolution of the transient, and some differences are encountered between ROSA/LSTF and PKL facilities. In particular, in the ROSA/LSTF pressure vessel there is a physical separation between the upper plenum and the upper head. However in PKL facility both parts are connected so coolant can flow from the upper plenum to the upper head and vice-versa. There is also a difference in the power distribution inside the core. Thus, while in PKL the power is uniformly distributed in all directions in ROSA/LSTF installation there is a radial and an axial power profiles, as explained in section 4.1. So, in order to verify the influence of the vessel design in the evolution of the main variables, three new models of PKL installation were developed in which the ROSA/LSTF vessel features are considered. The modifications studied are the following:

- PKL-A: PKL model considering there is no coolant path between the upper plenum and upper head of PKL reactor pressure vessel.

- PKL-B: PKL-A considering ROSAL/LSTF radial distribution.

- PKL-C: PKL-B considering ROSAL/LSTF radial and axial power distribution.

Fig. 9 shows the evolution of PCT obtained after the model changes and with PKL and ROSA/LSTF original models. In this Figure, it is observed that the closure of coolant path from upper plenum to upper head, PKL-A model, has a great influence in PCT evolution. Thus, calculations performed using PKL-A predict an advancement in the PCT excursion compared with the original PKL model. This advancement is the same as observed when comparing ROSA/LSTF with PKL original model calculations. The maximum PCT reached in the PKL original model is drastically reduced if the coolant path in the upper parts of the vessel is not permitted, as modelled in PKL-A. The new PCT value reached is similar to the one predicted by ROSA/LSTF calculations. The decrease and advancement in the maximum PCT can be explained by the advancement in the CET rising and by the core level evolution, presented in Fig. 10 and Fig. 11, respectively. On one hand, the evolution of CET temperature is similar to the PCT, that is, there is an advancement in the rising, so the set point for the activation of the accident management measures is reached earlier than in the PKL original model, as can be observed in Fig. 10, and the effectiveness of depressurization and safety injection from accumulators reduce the PCT rise. On the other hand, the evolution of the core level predicted in PKL-A model also influences the PCT values. In Fig. 11 it is observed that PKL-A corel level starts to decrease elarlier than the original model, but the decrease is smoother, so from 750s the level inside the core is higher for PKL-A run than for the original PKL. As the core inventory is higher, the temperature in the clad is maintained at lower values. Moreover, at $1200 \mathrm{~s}$ an increase in the core level in PKL-A model 
is observed, what stops PCT rising. In fact, a low decrease is observed when this phenomenon occurs (see Fig. 9). This behaviour is not reproduced in PKL original model, in which the level falls until $1400 \mathrm{~s}$, when the core is almost empty (see Fig. 7(d) and Fig. 7(e)). In order to asses if the root cause of the advancement is due to the coolant path blockage or the different power distribution, a model using the original PKL vessel and changing the radial and axial power distribution, as in ROSA/LSTF, has been run, but no advancement was observed. Regarding the maximum PCT value reached in PKL-A model, two phenomena explain such reduction. This suggests that in the original PKL model needs a deeper study on the coolant path circulation from the core to the upper plenum and upper head. Regarding the CET values, exposed in Fig. 10 , the same time advancement as PCT evolution is observed, but the maximum CET value is not reduced compared with the original PKL calculation. As the CET thermocouple is above the core, the increase in the level is not enough to reduce the rising in the mixture temperature, and the drop in the CET value is produced by the injection of the accumulators.

To assess the effect of the power distribution on the plant evolution variables, two models were developed starting from PKL-A. First the radial power distribution effect has been checked. PKL-A core model has been has been divided in three zones with different power generation, this change is implemented in PKL-B model. The radial distribution of the heat generated in the core has no influence on the rising time of PCT and CET, as can be seen in Fig. 9 and Fig. 10, respectively. But, the maximum value reached by both, PCT and CET, is reduced and delayed compared with PKL-A where all the power is generated in one zone. This effect is explained by the thermocouples position. Thus, the PCT measurement is now in a zone with less power production, so the value reached is lower. Regarding the CET, the thermocouple is located outside the core, so the temperature of the coolant is given by the mixture of temperatures of the flows coming from the three different heated zones of the core. Regarding the core level, the behaviour is similar to the PKL-A model. So, the radial power distribution has no significant effect on the core level behaviour (see Fig. 11).

Finally, PKL-C includes the blockage in the coolant path, the ROSA/LSTF model for radial and axial power distribution. In particular, the axial power distribution is divided in seven axial levels with different peaking factors. In this case, the PCT rising time is the same as in PKLA and PKL-B, and coincides with ROSA/LSTF predictions, but the maximum value reached is higher. Thus, in this model the different axial power profile increase the power generated in some axial levels, compared with the flat axial power profile used in PKL-B, so in some parts of fuel element the power generated is higher than considering the flat power profile and, consequently the PCT reaches a higher value. The effect on the CET produced by the consideration of the axial profile is negligible, as can be observed in Fig. 10, when comparing PKL-B and PKL$\mathrm{C}$ results. Although PCT maximum value is higher in PKL-C than in PKL-B the core vessel level is also higher. This effect is explained by the collapsed level definition as the liquid in the mixture changes with the power generation, and by the axial power distribution, as in the upper parts of the fuel elements that are uncovered the power generated is larger than if a flat profile is considered. 


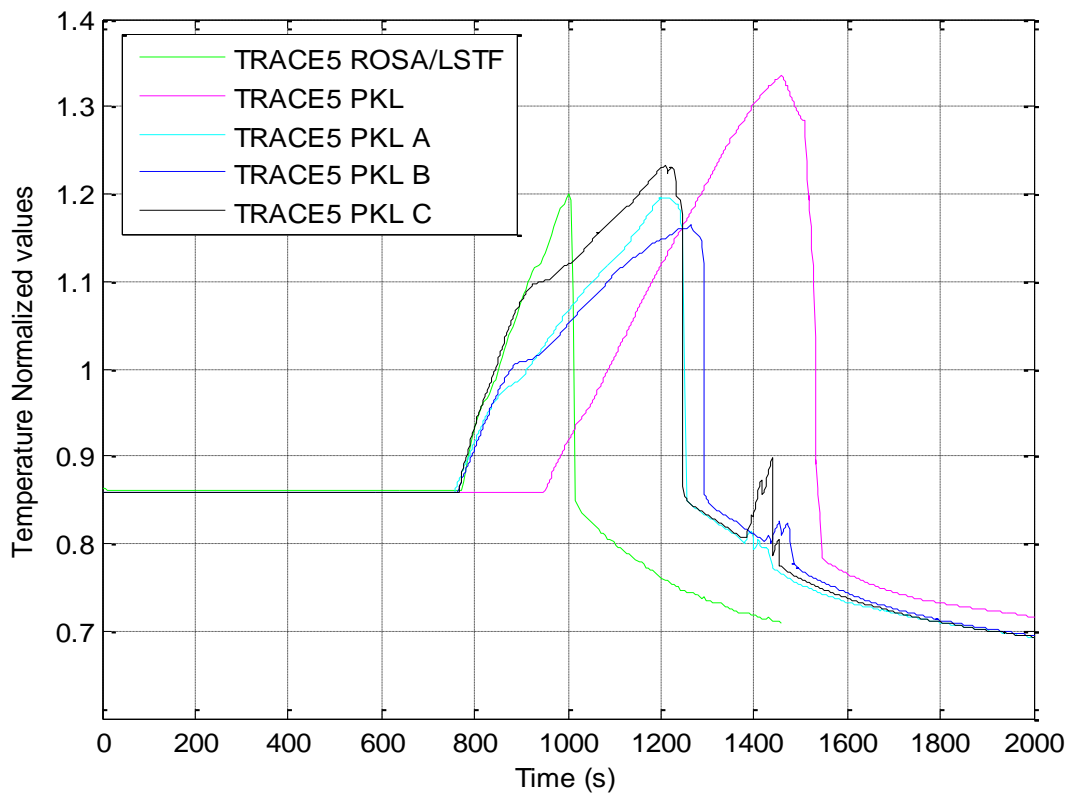

Figure 9: PCT evolution for ROSA, PKL, PKL-A and PKL-B models

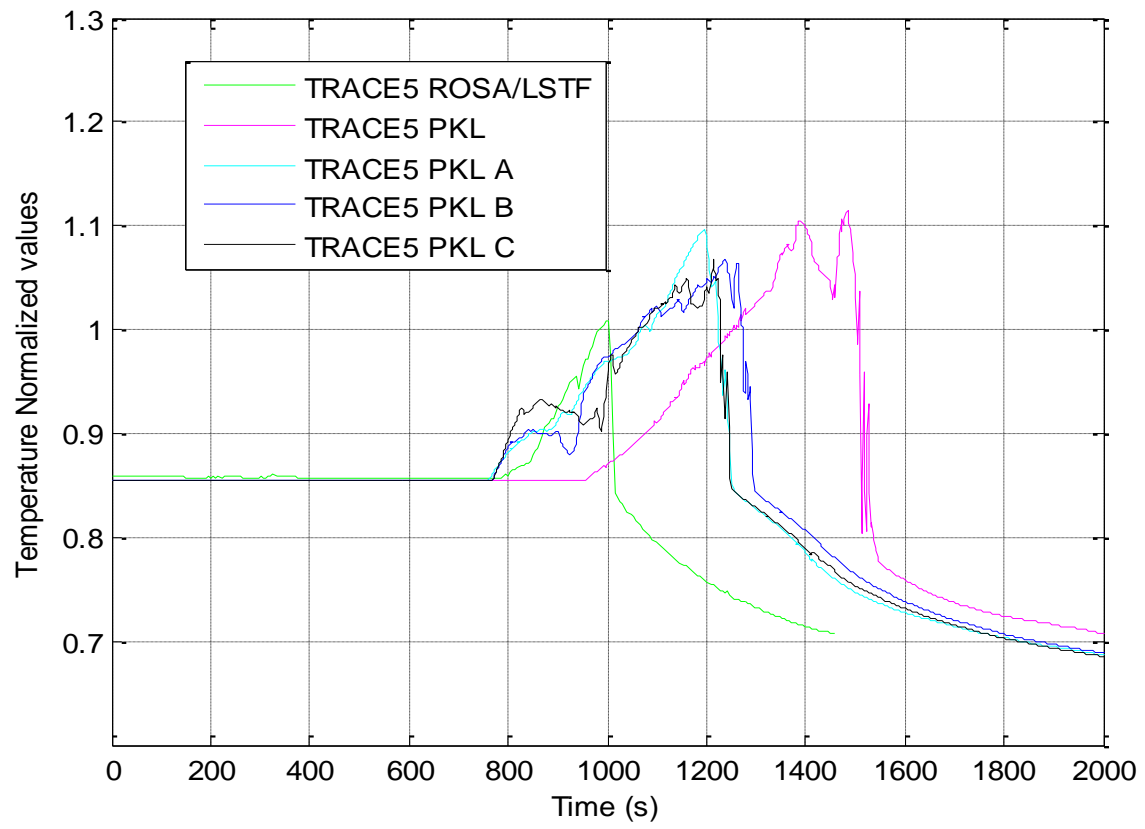

Figure 10: CET evolution for ROSA, PKL, PKL-A and PKL-B models 


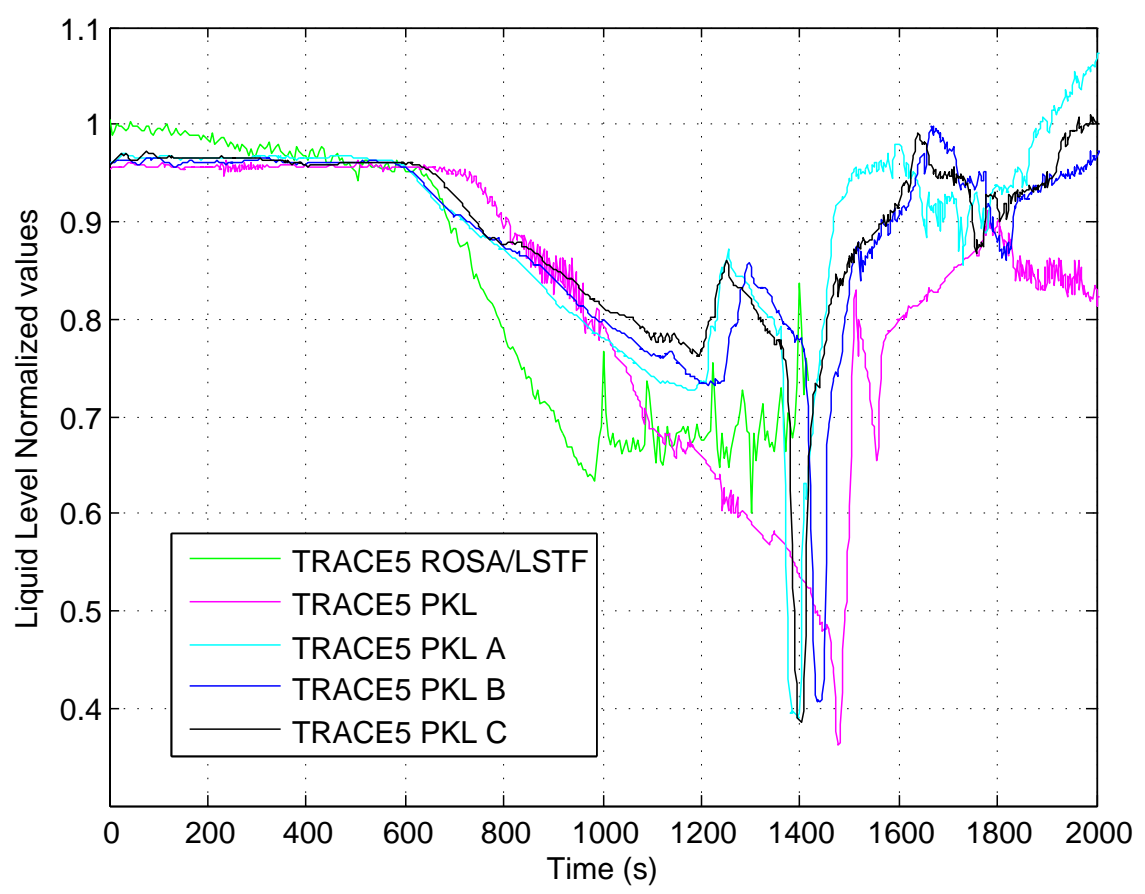

Figure 11: Core level evolution for ROSA, PKL, PKL-A and PKL-B models

\section{Conclusions}

The experiments undertaken in different facilities and inter-comparisons of the simulated results, usually performed in the frame of international programs, are used to improve the knowledge on codes performance and nuclear safety. In this paper a SBLOCA transient performed at ROSA/LSTF and PKL facilities has been simulated using TRACE code to analyse the CET measurements effectiveness to trigger the AM measures. A good agreement between the calculations predicted by TRACE for the behaviour of the main safety variables and their respective experimental data is observed for both, ROSA/LSTF and PKL. However, the mass coolant distribution inside the vessel predicted by TRACE in both models differs from the experimental data, and a more detailed study is needed on the vessels geometry features and loss coefficients to better reproduce the real coolant paths. Regarding the relationship between CET and PCT, it was observed that the calculations do not provide conservative values of PCT for all CET values what can affect plant safety.

The different timing in the events that take place in the transient can be caused by the scaling and differences in the technology. In this paper the design differences between both technologies studied are: The flow path between the upper plenum and the upper head, and the power radial and axial distribution showing that, when PKL model is modified with this features presented in ROSA/LSTF, TRACE predictions of the main variables of PKL installation are closer to the evolutions observed in ROSA/LSTF, what evidences the importance of the plant design in the evolution of the transient. 


\section{Acknowledgements}

This paper contains findings that were produced within the OECD-NEA ROSA and PKL Projects. The authors are grateful to the Management Boards of the ROSA and PKL Projects for their consent to this publication. This work is partially supported by the Grant-in-Aid for Scientific Research of the Spanish Ministerio de Educación (Grant number: AP2009-2600), the Spanish Ministerio de Ciencia e Innovación under Project ENE2011-22823, by the Grant-in-Aid for Scientific Research of the Vicerrectorado de Investigación, Innovación and Transferencia of the Universitat Politècnica de València, by the Consejo de Seguridad Nuclear under project CSNSIN/4078/2013/640 and by the Generalitat Valenciana under Project PROMETEOII/2014/008.

\section{References}

Applied Programming Technology, Inc. 2012. Symbolic Nuclear Analysis Package (SNAP).User's Manual. Version 2.2.1.

AREVA, 2012. Test PKL III G7.1: SB-LOCA with Total Failure of HPSI (Counterpart Testing with ROSA/LSTF) Quick Look Report - AREVA NP GmbH - NTCTP-G/2011/en/0008

Belaid, S.; Freixa J.; ZerkakVihavainen O., 2010. Analysis of the Test OECD-PKL2 G7.1 with the Thermal-Hydraulic System Code TRACE. NUREG/IA-0432. U. S. Nuclear Regulatory Commission, Washington.

Carlos, S.; Villanueva, J.F.; Martorell, S., Serradell, V. 2008. Analysis of a loss of residual heat removal system during mid-loop conditions at PKL facility using RELAP5/Mod3.3. Nuclear Engineering and Design 238(10), $2561-2567$.

Carlos, S., Villanueva, JF., Martorell, S., Serradell V. 2011. Simulation of the F2.1 Experiment at PKL Facility Using RELAP5/MOD3. NUREG/IA-0250. U. S. Nuclear Regulatory Commission, Washington.

Freixa J.; Manera A. 2010. Analysis of an RPV upper head SBLOCA at the ROSA facility using TRACE. Nuclear Engineering and Design 240 (2010) 17791788.

Freixa J.; Martnez-Quirogaa V.; Zerkakb O. and Revents F. 2015. Modelling guidelines for core exit temperature simulations with system codes. Nuclear Engineering and Design 286 (2015) 116-129.

Gallardo, S., Abella, V., Verdu, G. and Querol A. 2012. Assessment of TRACE 5.0 against ROSA Test 3-1, cold leg SBLOCA. NUREG/IA-0412. U. S. Nuclear Regulatory Commission, Washington.

Japan Atomic Energy Agency, 2003. ROSA-V Large Scale Test Facility (LSTF) system description for the 3rd and 4th simulated fuel assemblies

Japan Atomic Energy Agency, 2012. Final Data Report of ROSA Data Report of ROSA-2/LSTF (Counterpart Test PKL SB-HL-18 JAEA.

Jonnet, J.R., Stempniewicz M.M., de With, A., Wakker P.H. 2013. RELAP5 analysis of PKL, main steam line break test. Nuclear Engineering and Design 265, 755-764.

Martinez-Quiroga, V., Reventos F. and Freixa, J. 2014. Applying UPC Scaling-Up Methodology to the LSTF-PKL Counterpart Test. Science and Technology of Nuclear Installations.http://dx.doi.org/10.1155/2014/292916.

Nakamura, H., Watanabe, T., Takeda, T., Maruyama, Y., Suzuki M., 2009. Overview of recent efforts through ROSA/LSTF experiments. Nuclear Engineering and Technology 41(6), 753-764.

Toth I., Prior R., Sandervag O., Umminger K., Nakamura, H., Muellner N., Cherubini M., Del Nevo A., D'Auria F., Dreier J., Alonso J.R., Amri A.,2010. Core Exit temperature (CET) in Accident Management of NUclear Power Reactors. https://www.oecd-nea.org/nsd/docs/2010/csni-r2010-9.pdf

Querol, A., Gallardo, S. and Verd, G. 2014. Simulation of a SBLOCA in a hot leg. Scaling considerations and application to a nuclear power plant. Nuclear Engineering and Design http://dx.doi.org/10.1016/j.nucengdes.2014.10.006

Reventos, F., Freixa, J., Batet, L., Pretel, C., Luebbesmeyer, D., Spaziani, D., Macek, J., Kasahara, F., Umminger, K. 2008. An analytical comparative exercise on the OECD-SETH PKL 2.2 experiment. Nuclear Engineering and Design 23811461154.

Umminger, K., Mandl, R. and Wegner, R. 2002. Restart of Natural circulation in a PWR-PKL test results and s-RELAP5 calculations. Nuclear Engineering and Design 125, 39-50.

Umminger, K., Dennhardt, L., Schollenberger, S. and Schoen, B. 2011. Integral Test Facility PKL: Experimental PWR accident Investigation. Science and Technology of Nuclear Installations Vol 2012, 1-15.

USNRC. 2010a. TRACE V5.0 THEORY MANUAL Field Equations, Solution Methods, and Physical Models. U. S. Nuclear Regulatory Commission, Washington, DC 20555-0001.

USNRC. 2010b. TRACE V5.0 USER'S MANUAL Volume 2: Modeling Guidelines. U. S. Nuclear Regulatory Commission, Washington, DC 20555-0001. 